\title{
A CASE OF INFLAMMATORY PSEUDO-TUMOUR OF THE ORBIT
}

\author{
BY \\ Thomas Colley
}

WEYMOUTH

INFLAMMATORY pseudo-tumours of the orbit are relatively rare. Apart from this fact, the unusual nature of this particular case justifies its detailed description.

The case occurred in a boy, aged 13 years. He was brought to hospital in April, 1925, for a small chalazion in the left lower lid. It was while everting the lid that I noticed some limitation in upward movement of the globe. There was no apparent proptosis and the eye was normal in every way. On palpation, in the region of the trochlea, a slight resistance was felt.

On the right side the eye was absent and there was a contracted socket. The mother stated that the eye had been removed the previous year on account of a growth.

I was able to obtain a complete history from the notes of my predecessor. The boy had first attended hospital in March, 1923, with a moderate degree of proptosis of the right eye; the vision was then $6 / 9$. The mother said that this proptosis was variable. X-ray examination showed a doubtful opacity in the region of the right frontal sinus; rhinological examination was, however, negative.

The condition remained stationary until July of the following year (1924), when a very definite increase in proptosis was observed. A mass was felt below the brow coming forward from the back of the orbit. It was then decided to explore the orbit and an incision was made over the summit of the swelling and a portion removed for pathological examination. A section showed chronic inflammatory tissue, the suggestion being that it was probably tuberculous in origin.

After this operation a rapid increase in proptosis took place and is was proposed to remove the eye and contents of the orbit. Before giving her consent, the mother asked for a second opinion. She was sent to St. Bartholomew's Hospital, where the eye and orbital contents were eventually excised. I am indebted to Professor G. E. Gask for the following extract from the hospital notes :-

"When the eye was excised it was found that the superior rectus and superior oblique muscles were infiltrated by a hard growth, which also involved the posterior pole of the eyeball and optic nerve and filled the entire posterior part of the orbit. As much as possible of this growth was removed with scissors and then the cavity was packed with a radium tube." 
"Pathological Examination.-The mass was of a whitish colour, almost cartilaginous in consistency, and surrounding the optic nerve.

Microscopical section showed inflammatory tissue only. There were many fibroblasts in all stages with large numbers of round cells consisting chiefly of eosinophil and plasma cells. The condition appeared to be inflammatory and suggested a syphilitic origin."

("Both Wassermann and Sigma reactions were negative.")

Within 14 days of my seeing the case there was some proptosis of the remaining eye, with limitation of movement chiefly up and in. Just below the inner end of the brow a swelling could be palpated, it was a hard nodular mass which appeared to be coming forward from behind the globe.

Wassermann reaction was negative, both before and after a provocative dose of N.A.B. A differential blood count was normal. Rhinological examination produced a negative result and $\mathrm{X}$-ray was also negative. The urine was normal and the child generally appeared to be in perfect health.

The proptosis gradually increased until the lids barely covered the cornea. The eye was displaced down and out, and below the inner part of the brow, a nodular swelling could be seen. This swelling was hard and fixed; it gave the impression of a growth which was infiltrating the orbital tissues. The conjunctiva, up and in showed large congested veins and the central retinal vein also showed signs of obstruction.

The mother emphatically refused permission for an exploratory operation. She contended that a similar operation had only produced a worse state in the other eye.

Potassium iodide, in conjunction with mercury, was given, but unfortunately the iodide had to be stopped as each dose was followed by nausea and vomiting.

In spite of a negative Wassermann reaction I decided to start anti-specific treatment in the form of N. A. B. After a course of six injections, at weekly intervals, I thought that some improvement had resulted. There did not appear to be quite the same difficulty for the lids to cover the cornea. At the end of two months this improvement was definite. The injections were continued for a period of three months and then stopped. The improvement, although slow, was maintained, and in March of the following year (1926), 11 months after I had first seen the child, he could close the eye almost normally and movement was only slightly limited up and in. In the region of the trochlea the nodular mass could only just be felt where it was shrinking back in the orbit. It could be palpated for a further two months, but after that time no resistance could be felt to deep digital examination. Full 
muscular movement had returned by the end of the year. I have recently seen the patient and the eye and orbit are normal.

In considering this case, the chief question which arises is whether or not the tumour was gummatous in origin. It seems doubtful that a syphilitic lesion could be present in a boy of this age where the Wassermann reaction was so definitely negative, and where all stigmata of the disease were absent. And yet it is difficult to find a diagnosis to replace that of gumma, especially as the growth disappeared after a course of anti-specific treatment. Pathological examination would also appear to support the diagnosis of syphilis.

Williamson-Noble, ${ }^{1}$ in his paper on inflammatory pseudotumours, included a case where the pathological findings suggested the diagnosis of gumma. He also quoted three similar cases; one reported by Hine $;^{2}$ one extracted from the list of pseudo-tumours published by Benedict and Knight; ${ }^{3}$ and one referred to by Johnson Taylor ${ }^{4}$ in the Transactions of the Ophthalmological Society.

This last case is of considerable interest as, apart from the age of the patient, it is almost identical with the one which $I$ have described.

The patient was a woman, aged 30 years, whose eye was removed and orbit exenterated on account of a gradually increasing proptosis. On examination the pathologist diagnosed an organizing gumma. Some little time later the condition appeared in the remaining eye. In the light of the previous diagnosis mercury was pushed to such an extent that a diarrhoea resembling dysentery occurred. After this state had been reached the proptosis gradually subsided.

Musial $^{5}$ mentions a case of orbital tumour which might be included with the above as an orbital gumma.

It would appear that a diagnosis cannot be made with any degree of certainty in the majority of cases, and in order to differentiate between true and false tumours, a somewhat lengthy series of examinations has to be made. I can do no better than refer to the procedure suggested by Williamson-Noble which, although rather lengthy, forms an excellent basis for the examination of these cases.

\section{REFERENCES}

1. Williamson-Noble, F A.-Brit. Jl. of Ophthal., Vol. X, pp. 65-78.

2. Hine, Montague.-Trans. Ophthal. Soc. of the U.K., p. 181, 1922.

3. Benedict, W. M. and Knight, Mary S.-Arch. of Ophthal., pp. 582-593, 1923.

4. Taylor, Johnson.-Trans. Ophthal. Soc. of the U.K., p. 187, 1922.

5. Musial, A.-Zeitschr. f. Augenheilk., Vol. LXVIII, pp. 41-47, 1923. 